\section{Ideas of Reference}

Paul Newman

Department of Medical Psychology and Neuropsychology, Drake Center, Cincinnati, OH, USA

\section{Synonyms}

Referential delusion

\section{Definition}

A type of delusion in which a person incorrectly believes that circumstances or external events (i.e., comments, book passages, song lyrics, etc.) concern or are directed at him or her (have "reference" to one's self). Ideas of reference, like other delusions, are a symptom of psychosis.

\section{Cross-References}

D Delusion

$\checkmark$ Psychosis

\section{References and Readings}

American Psychiatric Association. (2013). Diagnostic and statistical manual of mental disorders (5th ed.). Arlington: American Psychiatric Publishing. 